\title{
Removal of Deuterium in Lithium Titanate by Sweep Gas Exposure $^{*}$
}

\author{
Akihito TSUCHIYA, Tomoaki HINO, Yuji YAMAUCHI, Yuji NOBUTA, Masato AKIBA ${ }^{1)}$ \\ and Mikio ENOEDA ${ }^{1)}$ \\ Laboratory of Plasma Physics and Engineering, Hokkaido University, Kita-13, Nishi-8, Kita-ku, Sapporo 060-8628, Japan \\ 1) Japan Atomic Energy Agency, 801-1 Mukoyama, Naka 311-0193, Japan
}

(Received 9 December 2011 / Accepted 27 April 2012)

\begin{abstract}
Lithium titanate, $\mathrm{Li}_{2} \mathrm{TiO}_{3}$, was irradiated with deuterium ions with energy of $1.7 \mathrm{keV}$ and then exposed to helium or helium-hydrogen mixed gas at different temperature, in order to evaluate the effect of exposure gas on removing deuterium from the pebbles. The amount of residual deuterium in the irradiated pebbles after the gas exposure was measured by thermal desorption spectroscopy. The mixing of hydrogen gas into helium gas enhanced the removal amount of deuterium. In other words, the amount of residual deuterium after the heliumhydrogen mixed gas exposure at low temperature was lower than that after the helium gas exposure. The ion irradiation followed by heating for the pebbles was repeated, and the residual amount of deuterium was measured. The residual amount increased with the number of irradiation/heating cycles. The result suggests that the tritium inventory in the blanket in a fusion reactor changes after the operation.
\end{abstract}

(C) 2012 The Japan Society of Plasma Science and Nuclear Fusion Research

Keywords: lithium titanate, deuterium ion irradiation, sweep gas, blanket, tritium inventory

DOI: $10.1585 /$ pfr.7.2405097

\section{Introduction}

In the blanket of DT fusion reactors, tritium is produced in the tritium breeding material due to nuclear reaction with neutron irradiation. Lithium titanate, $\mathrm{Li}_{2} \mathrm{TiO}_{3}$ is one of the most promising tritium breeding materials from the viewpoints of tritium release rate, thermal expansion and chemical stability. Water cooled solid breeder blanket has been developed as Test Blanket Module (TBM) [1]. The $\mathrm{Li}_{2} \mathrm{TiO}_{3}$ pebbles are employed in this blanket. In the region of tritium breeding material, the temperature and the pressure are estimated as from $573 \mathrm{~K}$ to $1173 \mathrm{~K}$ and about $0.1 \mathrm{MPa}$, respectively. The tritium generated in the $\mathrm{Li}_{2} \mathrm{TiO}_{3}$ pebbles will be swept and collected by using sweep gas [2]. As the sweep gas, helium alone or helium with a small amount of hydrogen gas will be employed. However, the mechanism on the tritium removal by the sweep gas has not been investigated in detail, and thus has to be clarified to improve the tritium recovery ratio.

In the present study, the $\mathrm{Li}_{2} \mathrm{TiO}_{3}$ pebbles were irradiated with deuterium ions in order to simulate the tritium generated in the pebbles of the fusion blanket, and then exposed to helium or helium-hydrogen mixed gas. The amount of residual deuterium in the pebbles was measured after the gas exposure. Then, we evaluated the effects of the sweep gas exposure on the removal of implanted deuterium in the pebbles.

\footnotetext{
author's e-mail: tsuchiya@frontier.hokudai.ac.jp

*) This article is based on the presentation at the 21 st International Toki Conference (ITC21).
}

\section{Experiments}

The $\mathrm{Li}_{2} \mathrm{TiO}_{3}$ pebbles fabricated by wet process were used as a sample. The characteristics of $\mathrm{Li}_{2} \mathrm{TiO}_{3}$ pebbles were estimated by K. Tsuchiya et al. [3,4]. The diameter of the $\mathrm{Li}_{2} \mathrm{TiO}_{3}$ pebble was approximately $2 \mathrm{~mm}$. The pebbles were degassed at $997 \mathrm{~K}$ for $1 \mathrm{~h}$ in a vacuum. After the degassing, the pebbles were introduced in the electron cyclotron resonance (ECR) ion source (Fig. 1) and irradiated with deuterium ions at RT. The ion energy was $1.7 \mathrm{keV}$ and the ion fluence was $3.0 \times 10^{18} \mathrm{D} / \mathrm{cm}^{2}$, at which the amount of retained deuterium was saturated $[5,6]$. The implantation depth of $1.7 \mathrm{keV} \mathrm{D}$ was about $45 \mathrm{~nm}$ calculated with SRIM code [7]. Then, in order to remove the implanted deuterium, the pebbles were exposed to helium or heliumhydrogen mixed gas for $1 \mathrm{~h}$ in the main chamber without a venting. The $1 \mathrm{~h}$ exposure was enough for almost implanted deuterium to be desorbed by heating more than $373 \mathrm{~K}$. The exposure pressure was $0.01 \mathrm{MPa}$. The fractions of helium and hydrogen in the mixed gas were $10^{4}$ and 1, respectively. The exposure temperature was taken at RT, $373 \mathrm{~K}, 473 \mathrm{~K}, 573 \mathrm{~K}$ or $773 \mathrm{~K}$. After the gas exposure, the amount of residual deuterium in the pebbles was measured by thermal desorption spectroscopy. The samples were heated by an infrared furnace from RT to $973 \mathrm{~K}$ with a heating rate of $10 \mathrm{~K} / \mathrm{min}$ and then kept at $973 \mathrm{~K}$ for $1 \mathrm{~h}$. The desorbed gases which contain deuterium atoms were quantitatively measured by a quadrupole mass spectrometer and the effects of the sweep gas exposure were evaluated. 


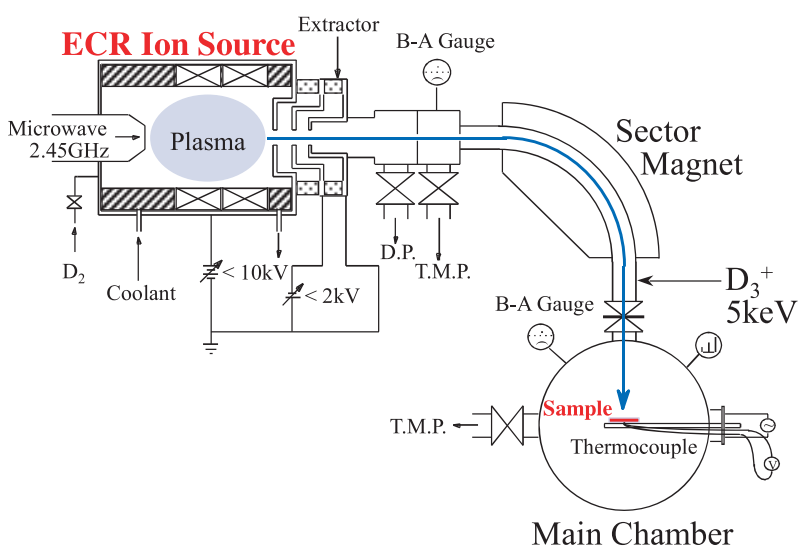

Fig. 1 ECR ion source.

In addition, in order to estimate the effects of repeated ion irradiation and heating, we conducted three times irradiation/heating experiments using the same sample. For this estimation, deuterium ion fluence was $3.0 \times$ $10^{18} \mathrm{D} / \mathrm{cm}^{2}$, and the exposure temperature was $573 \mathrm{~K}$.

\section{Results and Discussion}

Deuterium retained in the samples desorbed in forms of $\mathrm{HD}, \mathrm{D}_{2}, \mathrm{D}_{2} \mathrm{O}$ and HDO. Figure 2 shows thermal desorption spectra of $\mathrm{HDO}, \mathrm{D}_{2} \mathrm{O}, \mathrm{HD}$ and $\mathrm{D}_{2}$ from the samples exposed to helium gas at different temperatures. The major desorption peaks of HDO appeared at $580 \mathrm{~K}$ with the samples after the exposure at RT and $373 \mathrm{~K}$, and the most of HDO desorbed up to $500-620 \mathrm{~K}$. The peak at around $580 \mathrm{~K}$ was not observed for the samples after the exposure above $473 \mathrm{~K}$. Also, the desorption rate of $\mathrm{HD}, \mathrm{D}_{2}$ and $\mathrm{D}_{2} \mathrm{O}$ were much less than HDO gas and these gases were not observed from the samples exposed at more than $473 \mathrm{~K}$. Figure 3 shows that thermal desorption spectra of HDO from the samples exposed to helium or helium-hydrogen mixed gas at RT, $373 \mathrm{~K}$ and $473 \mathrm{~K}$. While the desorption peaks of the samples exposed to helium-hydrogen mixed gas at RT and $373 \mathrm{~K}$ also appeared at $580 \mathrm{~K}$, the desorption rates after the helium-hydrogen mixed gas exposure were small, compared to those after the helium exposure.

Figure 4 shows the amounts of residual deuterium atoms in the samples after the exposure to helium or helium-hydrogen mixed gas at different temperatures, or without the gas exposure. The amounts of residual deuterium atoms in the samples exposed to the heliumhydrogen mixed gas at RT and $373 \mathrm{~K}$ were less than those of the helium exposure samples. These results suggest that the isotope exchange would occur at the surface of the $\mathrm{Li}_{2} \mathrm{TiO}_{3}$ pebbles. The discrepancy of the residual amount between the samples decreased with the increase of the exposure temperature. The effect of thermal desorption might be dominant at higher exposure temperature. However, the effect of the hydrogen mixture on the deuterium removal still existed at $573 \mathrm{~K}$, as shown in Fig. 4 . The amounts of residual deuterium atoms in the samples ex-
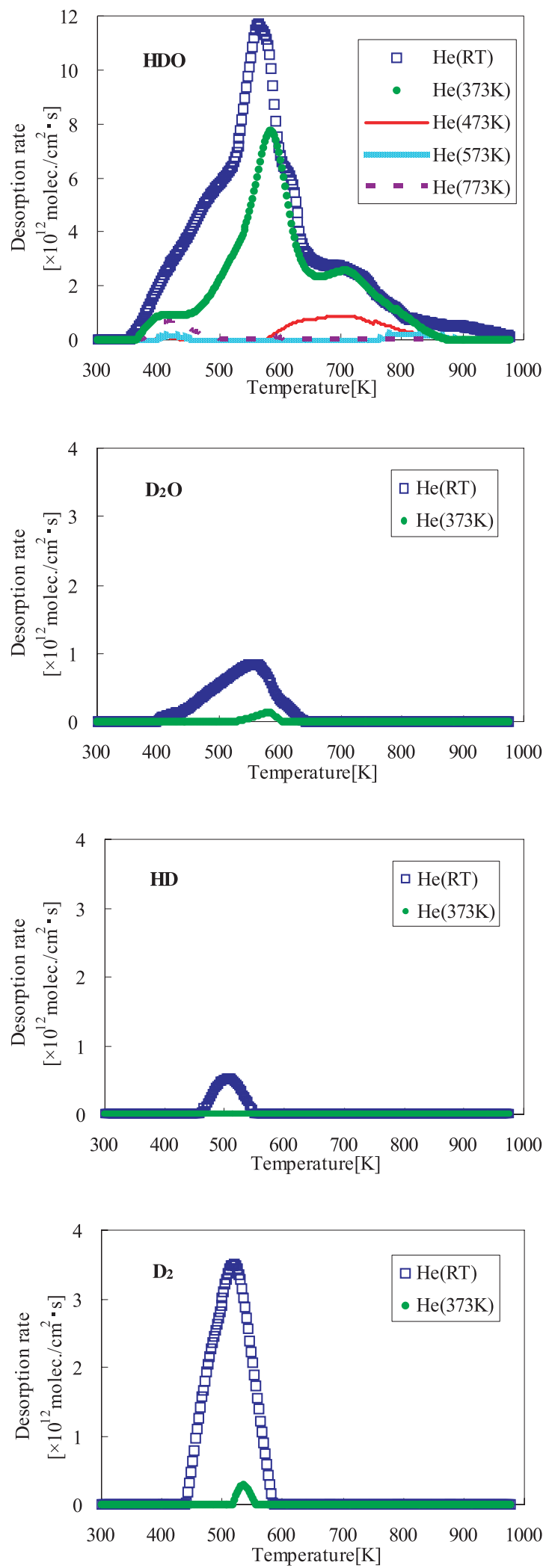

Fig. 2 Thermal desorption spectra of HDO, D2O, HD and D2 from the samples exposed to helium gas at different temperatures.

posed to helium or helium-hydrogen mixed gas at $573 \mathrm{~K}$ were $1 \times 10^{15}$ atoms $/ \mathrm{cm}^{2}, 0.05 \times 10^{15}$ atoms $/ \mathrm{cm}^{2}$, respectively, which corresponded to $5.4 \%$ and $0.3 \%$ of that in 

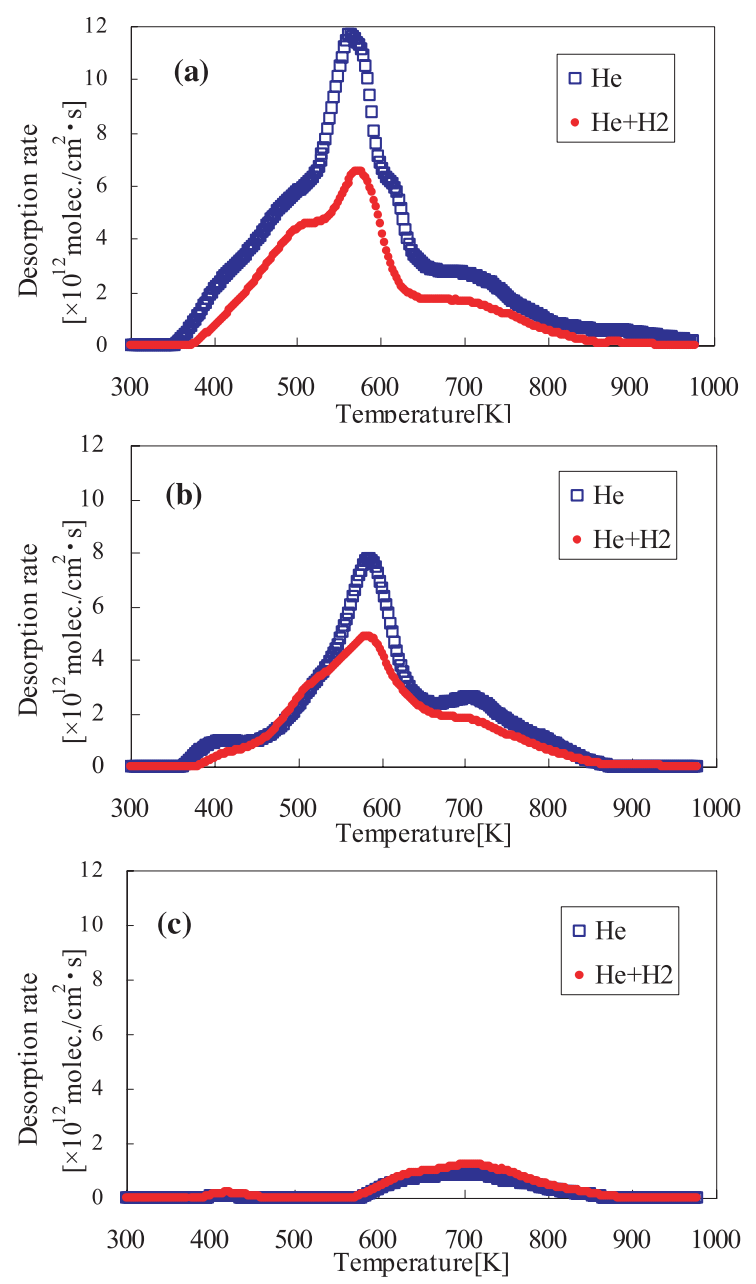

Fig. 3 Thermal desorption spectra of HDO from the samples exposed to helium gas $(\mathrm{He})$ or helium-hydrogen mixed gas $(\mathrm{He}+\mathrm{H} 2)$ at (a) RT, (b) $373 \mathrm{~K}$ and (c) $473 \mathrm{~K}$.

the sample without the gas exposure. In other words, the removal efficiency of helium and helium-hydrogen mixed gas at $573 \mathrm{~K}$ were approximately $94.6 \%$ and $99.7 \%$, respectively. Thus, the produced tritium in the actual fusion blanket seemed to remain partly, because the minimum temperature of the breeding materials was estimated at $573 \mathrm{~K}$ during the blanket operation. However, it was found that the addition of hydrogen to the sweep gas would help to remove tritium from the surface of the breeding material located at the low temperature region of the fusion blanket.

We also evaluated the change in the effect of deuterium removal with repeating irradiation/heating cycles for the same sample. Figure 5 shows the change in amounts of residual deuterium atoms in the samples with the number of the exposure/heating cycles. The presented values were ones after the subtraction by the data obtained from the sample which was exposed to helium gas $(0.01 \mathrm{MPa})$ at $573 \mathrm{~K}$ for $1 \mathrm{~h}$ without the ion irradiation as a background. The residual amount gradually increased with the number of the irradiation/heating cycles for both

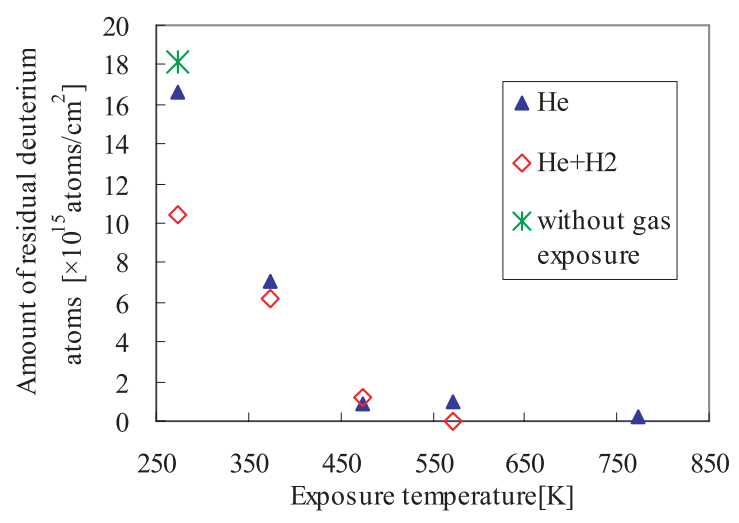

Fig. 4 The amounts of residual deuterium atoms in the samples after the helium gas (He) exposure or the heliumhydrogen mixed gas $(\mathrm{He}+\mathrm{H} 2)$ exposure at different temperatures. For reference, the amount of deuterium without the gas exposure was also shown.

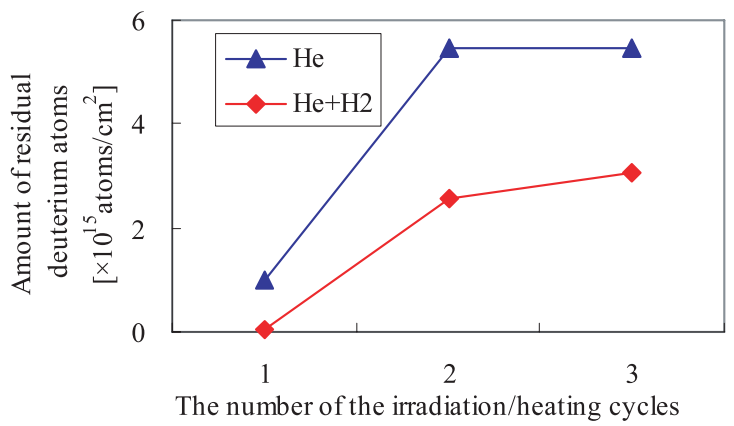

Fig. 5 Change in the amounts of residual deuterium atoms in the samples with the number of the exposure/heating cycles.

of the helium and the helium-hydrogen mixed gas exposure. The changes in the composition and the morphology of the pebble surface by the irradiation and the heating might be responsible for the change in the removal efficiency. These results suggested that the tritium inventory in the blanket and the effect of the sweep gas on the tritium removal change during the operation periods, because the pebbles received the heat cycle and particle load during the operation. Further investigations on the effects of the irradiation/heating cycles will be necessary.

\section{Conclusion}

In the present study, the simulation experiment for tritium removal by using sweep gas was conducted. The deuterium was employed instead of tritium. First the $\mathrm{Li}_{2} \mathrm{TiO}_{3}$ pebbles were irradiated with deuterium ions and exposed to helium or helium-hydrogen mixed gas at different temperature to remove implanted deuterium in the pebbles. Secondary, the amount of retained deuterium was measured by using a technique of TDS.

In the desorption spectrum of deuterium, the major desorption peaks were observed at $580 \mathrm{~K}$ in the samples exposed to helium or helium-hydrogen mixed gas at RT 
and $373 \mathrm{~K}$. In both cases of gas exposure, the amount of residual deuterium decreased with the increase of the exposure temperature. The amounts of residual deuterium in the samples after the exposure to helium-hydrogen mixed gas were lower than those after the exposure to helium gas. The result shows that the sweep gas with a small amount of hydrogen is certainly effective for reduction of tritium inventory in the blanket of a fusion reactor.

We also investigated the influence of repeating irradiation/heating cycles for the same sample. The amount of residual deuterium gradually increased with the number of the irradiation/heating cycles. This result suggests that the tritium inventory in the blanket changes after the operation in a fusion reactor.
[1] Japan Atomic Energy Agency Report, JAERI-Review 2005-011, 2005.

[2] S. Tanaka, M. Akiba, M. Enoeda, A. Hasegawa, S. Konishi, T. Muroga and A. Sagara, J. Plasma Fusion Res. 81, 434 (2005).

[3] K. Tsuchiya, H. Kawamura, K. Fuchinoue, H. Sawada and K. Watarumi, J. Nucl. Mater. 258-263, 1985 (1998).

[4] K. Tsuchiya, A. Kikukawa, T. Hoshino, M. Nakamichi, H. Yamada, D. Yamaki et al., J. Nucl. Mater. 329-333, 1248 (2004).

[5] T. Hino, D. Sato, Y. Yamauchi, H. Tanigawa, M. Akiba and S. Suzuki, Fusion Eng. Des. 83, 1173 (2008).

[6] T. Hino, H. Shibata, Y. Yamauchi, Y. Nobuta, S. Suzuki and M. Akiba, J. Nucl. Mater. 417, 713 (2011).

[7] http://www.srim.org/ 